\title{
Changes That Should Remain in Higher Education Post COVID-19: A Mixed-Methods Analysis of the Experiences at Three Universities
}

Águeda Benito, $\mathrm{PhD}$

Cintana Education, Tempe, Arizona, United States

(iD https://orcid.org/0000-0003-3779-3190

Kubra Dogan Yenisey, LLM, DES

Istanbul Bilgi University, Istanbul, Turkey

Kavita Khanna, $\mathrm{PhD}$

NorthCap University, Gurugram, Haryana, India

Manuel Felipe Masis, MS

Universidad Latina de Costa Rica, San Jose, San Jose, Costa Rica

Rosa Maria Monge, MS

Universidad Latina de Costa Rica, San Jose, San Jose, Costa Rica

Mehmet Ali Tugtan, $\mathrm{PhD}$

Istanbul Bilgi University, Istanbul, Turkey

Luis Diego Vega Araya, $\mathrm{PhD}$

Universidad Latina de Costa Rica, San Jose, San Jose, Costa Rica

(iD) https://orcid.org/oooo-0o03-3791-8440

Rekha Vig, $\mathrm{PhD}$

NorthCap University, Gurugram, Haryana, India

Contact: abenito@cintana.com

\section{Abstract}

Objectives: The goal of the present study is to describe how the transition to remote emergency delivery was addressed in three universities during the COVID-19 pandemic, to determine the satisfaction levels of their students and faculty with this new teaching-learning experience, and to gather their opinions about the future of higher education. 
Method: The study uses a mixed-methods approach, including faculty and student surveys and focus groups

Results: The study shows high satisfaction with the emergency remote delivery and clearly reflects the relevance of enhancing the digital components of future learning experiences in higher education and a unanimous preference for hybrid education. Participants provide recommendations to institutions regarding what students and faculty would like to keep for a more effective learning experience when the new normal comes.

Conclusions: COVID-19 has had terrible consequences; however, the pandemic has brought along some positive effects and improvement opportunities in higher education, and, if the results of the present study are any indication, the future of face-to-face higher education should be hybrid.

Implication for Theory and/or Practice: The study results can provide recommendations and inform decision-making by institutional leaders and policy makers regarding the necessary enhancement of the digital component of the teaching and learning process in higher education.

Keywords: COVID-19; hybrid higher education; emergency remote delivery; digital enhancements; online learning

Date Submitted: November 27, 2020 | Date Published: January 4, 2021

\section{Recommended Citation}

Benito, A., Yenisey, K. D., Khanna, K., Masis, M. F., Monge, R. M., Tugtan, M. A., Araya, L. D. V., Vig, R. (2021). Changes that should remain in higher education post COVID-19: A mixed-methods analysis of the experiences at three universities. Higher Learning Research Communications, 11, 51-75.

https://doi.org/10.5590/10.18870/hlrc.v11io.1195

\section{Introduction}

The COVID-19 pandemic has caused a global crisis of an unprecedented nature. We have seen most of the pillars of modern society being affected. The guiding principles of economies, health systems, human interactions, and education, and their rules and established forms have been transformed to a degree that it is hard to imagine how any of them would ever go back to what they were before.

In the case of education, technology has been the protagonist. Physical campuses have been closed for months now, and many universities have been able to continue to serve students online only because of the level of global connectivity and the extraordinary development that educational technology has reached. These scholars all over the world, some of them hesitant until now, have had to experience a new mode of academic delivery.

It is impossible to replicate fully online models in such a short time, but in their shift to emergency remote modality, universities have had the chance to at least be inspired by many of the best practices developed from more proficient online initiatives. Many challenges have been described during the rapid transition, but at least some key difficulties of online learning did not even have to be addressed. For example, faculty members know their students personally, which makes it easier for them to create more humanized relationship. Thus, availability and dedication of students should be higher than for typical online students.

In essence, having had millions of university students and faculty teaching and learning online for some months constitutes a global laboratory that the authors of the present study have perceived as an exceptional opportunity for research. The three participating institutions were brought together by a new global network of universities called the Cintana Alliance (https://www.cintana.com/). They are located in Costa Rica, India, and Turkey, respectively, and together they carried out a collaborative research project which analyzed the 
satisfaction levels of students and faculty with their emergency remote educational experience and, most importantly, captured their opinions about the future of higher education.

\section{Literature Review}

Much has been written about the past, present, and future of online education. Digitalization of higher education seems inevitable, and numerous studies even show the analogy in its development with the evolution of other industries, and with e-commerce in particular. Pathak (2016) defended the idea that universities will not exist in their current form and will need to add the online component to the physical campus experience.

At an institutional level, multiple case studies and best practices regarding online education can be found. As an example, Moreira (2016) presented the successful trajectory for developing an online operating mode at a campus-based university in the Northeastern United States. The author highlights the institutional strategy, which focused on internationalization and inclusion, as well as the thorough reflections and readiness initiatives that preceded execution. Comprehensive measures, including technical, pedagogical, and financial, were implemented and supported by a very robust professional development plan.

The factors impacting effective online instruction have been extensively researched as well. Sun and Chen (2016) reviewed 47 published studies on online teaching and learning since 2008, concluding that effective online instruction is dependent upon several factors, including (a) well-designed course content; (b) motivated interaction between the instructor and learners; (c) well-prepared and fully supported instructors; (d) creation of a sense of online learning community, and (e) rapid advancement of technology. Based on these pillars, the authors provide practical suggestions for those who are planning to develop online courses. Furthermore, evidence-based quality frameworks for the development and delivery of online courses have been published. Vlachopoulos (2016) presented a comprehensive study based on an exhaustive meta-analysis of available literature and proposed a quality roadmap to guide future steps for institutions.

Student engagement in online learning has been amply covered in the research. Dumford and Miller (2018) analyzed the National Survey of Student Engagement (NSSE) data from 2015, where more than 300,000 students at 541 United States institutions participated. The authors concluded that those students taking greater numbers of online courses were more likely to engage in quantitative reasoning. However, they were less likely to engage in other essential aspects of the learning process, such as collaborative learning, studentfaculty interactions, and discussions; authors encouraged universities to apply greater efforts in this area. There are several factors that influence the fluctuation of engagement in students during the extent of an online course, including lecturer's presence, workload, content, assessment, work-life commitments, and others (Muir et al., 2019)

In a study of United States students, Ortagus (2017) found that being a full-time employee, a parent, and married were positively related to enrolling in courses or programs. The study also concluded that fundamental challenges still remain; for example, economically and socially disadvantaged students are typically less likely to engage with online education. Diving deeper into the idea of authentic accessibility, Lee (2017) noted that increasing the accessibility of university education is a complex and multidimensional social issue that requires further definition and implementation efforts in online higher education.

Beyond the formal body of knowledge about online education, very soon after the fast transition to the emergency remote modality took place, universities and higher education experts started to share their experiences and considerations. An incredibly abundant number of webinars and online summits, as well as publications, such as blogs, white papers, opinion articles, and case studies, shared reflections, generous recommendations, and adventurous predictions about the future of higher education. Some of these activities 
include the 2020 virtual Arizona State University and Global Silicon Valley (ASU+GSV) summit (https://gsv.ventures/virtual-summit-series/), the 2020 Times Higher Education (THE) Mini-Summit (https://www.timeshighereducation.com/events\#survey-answer), the recent webinars of the European Association of International Education (EAIE) (https://www.eaie.org/training/webinars.html), multiple online meetings, university panels and free virtual conferences such as QS 2020

(https://qsinconversation.com/?utm_source=qs.com\&utm_medium=text_link) or REMOTE faculty summit hosted by Arizona State University in the United States (https://www.theremotesummit.org/). Numerous online courses regarding online teaching have also been made available (e.g., Petrone, 2020). Additionally, we have been educated by countless numbers of informative publications, hundreds of articles about the initial response of universities to the crisis from The Chronicle of Higher Education or from Inside Higher Ed (e.g., see Lederman, 2020). Inside Higher Ed's most recent release, Taking Colleges Online: How Smart Institutions and Their Leaders Can Approach Online Education Now and in a Postcoronavirus World (McKenzie et al., 2020), addressed faculty members and administrators tasked with improving online instruction. Prestigious online education experts, such as Quality Matters (Crawford, 2020), have also responded quickly with resources to assist remote instructors. Some of the tips and recommendations for institutions moving from emergency remote to online quality education present useful ideas.

Numerous papers addressing case studies and innovative pedagogical and technological recommendations at an institutional, local, or global level have been generated. An interesting example is the recent publication by Daniel (2020), who offers guidance to institutions regarding the preparations they should make to address students' needs by level and field of study, including his recommendations to take advantage of asynchronous learning in this new setting. Bao (2020) focuses on six instructional strategies that were incorporated in Peking University, where 2,613 undergraduate courses and 1,824 graduate courses went online during the pandemic. The article notes strategies such as dividing teaching content into smaller units to help students focus, emphasizing the use of the teacher's voice to make oral communication as effective as possible, even if an image is not available, and strengthening students' active learning ability outside of class. Benito and Díez (2020) also addressed recommendations to deliver quality education in this new environment, mainly referring to the role of faculty, learning resources, and technology. Toquero (2020) identified opportunities for higher education in the Philippines to respond to the educational problems that arise due to the COVID-19 pandemic. The author made academic recommendations, such as the migration of courses, the alignment of curriculum competencies, and scaling teachers' training for online learning instruction, as well as nonacademic initiatives, such as strengthening environmental policies and hygiene practices and the implementation of an online mental health service. Sahu (2020) believes that the health and safety of students and staff should be the top priority and discussed a number of measures universities should implement, including counseling services to support the mental health and well-being of students.

More broadly, Langella (2020) discussed the consequences of the pandemic on higher education, presenting a thought-provoking point of view regarding how the expected economic recession will affect local and international enrollments in the United Kingdom. Strielkowski (2020) referred to the digital transformation that the COVID-19 pandemic has initiated. The author showed how innovations in academia that would have normally taken years to implement due to rigid regulations and unquestionable practices were rapidly introduced in a matter of days. Blankenberger and Williams (2020) also discussed the impact of COVID-19 on higher education by analyzing the role the pandemic can play in reshaping public administration and policy systems. In particular, the authors focus on key areas of potential impact, including budgeting, enrollment and recruiting, research, course delivery, and accountability and assessment. Through this, the authors defended the role higher education needs to play in advancing social equity during the COVID-19 pandemic and post COVID-19.

In the context of their applicable regulations, many universities are now immersed in the process of giving shape to the type of higher education they should be providing to their students in the future. There are many 
resources that can help universities, with the common themes being the idea that technology will continue to play a protagonist role and that the digital component of the learning experience is here to stay. However, the existing literature does not provide much information regarding the necessary input from students and faculty, which the present paper aims to address.

More specifically, the purpose of the present study is to examine the satisfaction levels of students and faculty with their recent online experience. Additionally, it is our intent to present the student and faculty recommendations regarding the future of higher education. Faculty and students have undergone the change of modality in person, and we believe that their opinions regarding the most effective components of their experiences will be a necessary input to the definition of the future educational strategy of universities.

\section{Going Online Overnight: The Experiences of Three Universities}

The only alternative for thousands of universities to continue to serve their students during the COVID crisis was to transition to online delivery. There was no time for hesitation; institutions had to get ready in a matter of days, identify and set up technology, and prepare faculty and students for a new mode of delivery. As an illustration, this section briefly describes how three very distant universities (located in Costa Rica, India, and Turkey) approached the situation and the initial reactions of their students and faculty.

\section{Istanbul Bilgi University}

Istanbul Bilgi University (referred herein as Bilgi) is a comprehensive higher education institution located in Turkey. It was founded in 1996 and presently enrolls 20,000 students in over 150 degree programs in various disciplines and all levels of higher education. Online education in Bilgi started in 2000, when Bilgi launched its first online Master of Business Administration (e-MBA) program. By 2009, in line with the developments in online education around the world and in Turkey, Bilgi decided to further this initial step by launching other online graduate programs, as well as integrating online and blended courses into its face-to-face undergraduate programs. Since then, Bilgi developed operational capabilities to design and implement digital learning content with its own film production studio, online course recording and broadcasting facilities, dedicated technical and pedagogical teams, and an accumulated institutional know-how on distance education. On average, at the start of 2020, $16 \%$ of Bilgi's students were learning online.

When the COVID-19 outbreak rendered face-to-face education impossible, the Turkish Board of Higher Education stipulated that those universities with the capability to do so could proceed with distance education for the remainder of the term. After careful consideration, the university switched to emergency remote teaching. According to the Turkish Board of Higher Education data (2020), a total of 189 Turkish universities switched to distance education. Bilgi's intensive preparation process started on March 17, and multiple actions were taken before the commencement of online classes on March 23. Actions included:

- The university identified the courses suitable for completion through distance education. A total of 1,815 courses were listed.

- The pedagogical and technical training programs for faculty that had been developed previously were adapted for emergency remote teaching purposes.

- Students were informed through e-mail and text on the updated academic schedule, and a call center hotline was implemented to channel student inquiries about distance education to relevant administrative and technical departments through a ticket system.

- The university conducted 23 webinar sessions on the pedagogical and technical aspects of distance education, covering 11 different topics for a total of 2,836 participants in 9 days. All sessions were 
recorded, and these recordings were then edited so that students and faculty who could not join the live seminars could reach the content either in its entirety or sort through different topics and modules for relevant information.

- Additionally, all faculty members whose courses were to commence on the March 23 received individual calls over the weekend of March 19 for a total of 800 calls. Faculty members could then ask any questions and share any problem, need, or request they had. In some situations, faculty members even expressed that they had outdated personal equipment at home, and their office computer was delivered to them personally so that they could do their remote work effectively.

- A faculty member was designated as online coordinator in each academic program. Responsibilities included weekly reports of academic activities.

As a result of these measures, Bilgi commenced with 1,815 courses and conducted $80 \%$ of these courses through synchronous online classes. As of May 5th, 214 synchronous online midterm exams were completed while the rest of the grading and evaluation was done through projects and other asynchronous assignments. The ticket system processed an average of 75 inquiries per day during the first week of courses. By the final week, this number had dropped down to 21.

One other relevant fact that needs to be mentioned is that Bilgi University distributed computers to some of the students who did not have an available computer, but it was not possible to cover all, and even worse, some did not even have an internet connection at home and had to quit their studies, unfortunately not being able to enjoy the benefits of online education.

\section{The NorthCap University}

The NorthCap University (NCU) was established in 1996 under the name of Institute of Technology \& Management as the first private engineering college in the State of Haryana (India). It was awarded university status in 2010. NCU has 3,000 students enrolled in undergraduate and graduate programs corresponding to three schools: Engineering and Technology (the largest), Business, and Law. NCU has very limited experience in online education. Only since 2019 have students been able to enroll in a limited number of online courses, which are complemented by one hour per week of face-to-face facilitation and academic support.

On March 13, the government of India mandated closure of all the educational institutions due to the COVID19 pandemic. This was done without further guidelines regarding remote education. NCU understood the gravity of the situation and took a proactive decision to start online classes on March 16 to ensure academic engagement and continuity of education for the students. Care had to be taken at each step in the transition since no other university had at that point undertaken this initiative. On March 13, the entire IT team did a thorough analysis of all the available platforms in the market. The team considered various parameters including ease of use, inclusion of files, assignments, quizzes, and security. Since the institution had licenses for Office 365, Microsoft Teams was selected as the tool/platform for online teaching.

On March 14, all the faculty members of NCU were given training on working with Microsoft Teams. Some faculty members created videos on YouTube to explain the entire process of going online through Microsoft Teams. These two days were full of challenges, and the faculty worked overnight with the entire IT team to make sure the transition was smooth. Students were informed about the new learning modality, and on March 16 , live interactive classes were running online. As a complement to their classes, the university also promoted the enrollment of students in Massive Open Online Courses (MOOCs), taking advantage of the 5,00o student licenses that NCU had for online courses with certification from Coursera. This initiative was very well accepted, helping students not only to have the opportunity to enhance their learning, but to also appreciate a richer exposure to online education. 
NCU did its best to address the overall teaching and learning experience of the faculty and students in a comprehensive manner. The mental health of the students and faculty was a key consideration during the transition. The medical officers of NCU were on call to all students and staff members. Indian culture promotes meditation to reduce stress and increase focus and concentration. Realizing the importance of meditation, NCU connected with a meditation center that provided a meditation app for the NCU family.

During the transition, NCU proved that it was sufficiently savvy from a technological perspective, which allowed the institution to embrace the change with a high level of comfort. Continued support was provided to faculty until the academic year ended, mainly in the form of webinars, demonstrations, and presentations of new tools. The entire experience was emotionally and intellectually fulfilling for the faculty, since they could continue providing quality education to the students.

From the very beginning of this process, the students were quite receptive to the idea of online teaching. The platform used for delivering online lectures was quite conducive and compatible with smartphones as well, so if students did not have a laptop, they could still attend lectures. After the first couple of weeks, students were surveyed regarding their remote learning experience, and their opinions were analyzed. Immediate actions were taken to address some of their recommendations, such as making recorded classes available, reducing the total hours for practicals/experiments, and providing breaks in between long lectures. These changes made the upcoming weeks run smoothly.

\section{Universidad Latina de Costa Rica}

Universidad Latina de Costa Rica (referred herein as ULatina) was founded in 1979, offering at present approximately 100 academic programs, most of them at an undergraduate level in the following areas: engineering, health sciences, business, communication, and design. It currently has 25,000 students, and its main campuses are located in San José de Costa Rica. Here, many of its students attend face-to-face classes. Some of the continuing education programs are delivered online with a group of faculty participants, which has provided the university with some very valuable experience.

In Costa Rica, the first confirmed case of COVID-19 was announced on March 6 (Ministerio de Salud, 2020). That same day, Costa Rican private universities lead by the Rector of ULatina requested permission from the Board of Higher Education to allow online instruction for the rest of the term (Cerdas \& Bosque, 2020). Even though the formal answer was not provided until several weeks later, the University started considering online as a possible scenario, and preparatory tasks started. On March 16 (the 1oth week of a 15-week term), the government declared a state of national emergency and suspended all face-to-face classes. Other measures taken included closing the national borders, suspending all religious services, concerts, contact sports, and massive events, prohibiting the use of automobiles between $7 \mathrm{pm}$ and $5 \mathrm{am}$, in addition to other measures (Ministerio de Salud, 2020, March 16).

Anticipating the country's decision to suspend face-to-face interaction, ULatina created a commission that led the process of moving to online instruction in a matter of days. This commission started working during the second week of March. After assessing the available infrastructure and experience of the faculty with online instruction, the commission decided to: (a) incorporate a new e-learning platform (Microsoft Teams) as a supplement to Moodle, the learning management system the university has been using for several years; (b) develop new training manuals and videos and share them with faculty just a few days before the online instruction started; and (c) conduct webinars during the weekend of March 14 and 15 to prepare faculty for the transition.

During the transition week, several follow up meetings were conducted with deans, department heads, and campus coordinators to detect support needs for each area. Connectivity problems and overload of the Moodle platform were detected. Alternative ways to complete classes were offered to those students experiencing 
connectivity problems. The Moodle platform was moved to a more robust server to avoid overload problems. The library adapted its policies to allow faculty without access to a reliable PC or laptop to be able to check one out to take home. There was an effort to offer recommendations, tools, and support to faculty members with the goal of making the transition as smooth as possible.

ULatina conducted an early evaluation of student and faculty satisfaction a week after implementation. Participants mostly indicated adequate levels of satisfaction, and they provided recommendations that helped the institution adapt to the new reality, needs and expectations. In retrospect, it seems that faculty and students at ULatina were able to move from the face-to-face type of instruction to an online modality with relative smoothness and without much suffering.

\section{Purpose of the Study}

There were four main purposes of this study. The first was to understand the perceptions of students and faculty regarding their online experience in comparison with their previous face-to-face experience. The second was to discover what they enjoyed and found most effective about their online teaching and learning experiences. The third was to identify any interesting elements of their online learning experience that they would like to keep when things go back to normal. Finally, it was important to understand the opinion of students and faculty regarding the future of higher education based on their experiences with the emergency remote transition.

\section{Methods}

We conducted the present study according to a mixed-methods approach in which quantitative (first) and qualitative (second) information was collected sequentially. The most effective approach in the social, behavioral, and education sciences is often collecting and integrating quantitative and qualitative information (Núñez-Moscoso, 2017). Analyses of the information obtained from the students and faculty were conducted separately, and then results were connected.

The first step was compliance with the ethical considerations according to the internal mechanisms of each institution. The three universities submitted their proposals and their respective commissions informed positively about the key ethical aspects under consideration: informed consent, voluntary participation, confidentiality, anonymity, and do no harm in all cases.

\section{Procedures}

\section{Quantitative}

During the first part of the study, all faculty and students were sent an e-mail requesting their participation, with a link to the online survey included. Before the survey was administered, faculty and students were informed about the study and they gave their consent to participate. Both surveys were anonymous, and the information was collected via Google forms.

\section{Measures}

Two surveys were administered, one to students (Appendix A) and one to faculty (Appendix B). Both surveys consisted of four different types of questions: demographic information, several Likert questions (whenever possible using an even 1-4 scale), some binary (yes/no) questions, and some multiple-choice, non-excluding questions. The participants were asked to compare their online teaching/learning experience with their previous face-to-face experience. They were also asked to identify the elements of their experience that they would like to keep in the future and to indicate their preferred teaching/learning modality. 


\section{Statistical Analysis}

The general analysis was conducted with Microsoft Excel, and descriptive statistics utilizing means and percentages were produced. For the comparative analysis between the responses of the three universities, a series of chi-square tests of goodness-of-fit were performed to determine if the difference in the results was statistically significant.

\section{Qualitative}

In order to obtain the qualitative information, an e-mail was sent to a total of 30 students and another 30 faculty members, informing about the project and asking them if they would like to participate in the focus group sessions. To ensure enough diversity of participants, the local researchers at the three institutions identified 10 faculty members and 10 students each, including male and female, with different backgrounds and levels of academic experience. A total of 22 volunteer faculty members and 17 students joined the seven online focus groups that were conducted, three of them with faculty and another four with students.

Before the sessions started, the participants gave their consent to record the sessions. All the focus groups were conducted by one or two of the authors of this paper and, in order to ensure the comparability between the three universities, they followed some general recommendations and a common thread. There was a general introduction to all, and the context was set (this year has been very different, since mid-March the University has been delivering its courses online). All sessions lasted approximately 1 hour.

The qualitative information was then obtained, assuming that discourse analysis (van Dijk, 2018) would add valuable information regarding the opinions of students and faculty members, contributing to the better understanding of the purely statistical analysis.

\section{Measures}

The following questions were addressed in a semi-structured mode: (a) Can you describe what your experience has been like? How does it compare with your previous face-to-face experience? What were the advantages and challenges? (b) What did you enjoy the most during the transition? And (c) would you like to keep anything of this recent experience when we get back to the face-to-face classes in the future? At the end of the session, faculty and students were asked to share any final thoughts and remarks.

\section{Analysis}

The analysis of the focus groups was based on the recorded sessions and the notes from the facilitators. The discourse analysis consisted of reviewing the complete recordings at least twice, which allowed the identification of most frequent/relevant concepts and the elaboration of a descriptive narrative and a table showing the key concepts for each one of the topics addressed. The full analysis from each focus group was conducted by two individuals separately, and then analyses were shared, discussed, and integrated.

\section{Results}

\section{Quantitative}

\section{Student survey}

The survey for students was conducted during the month of May 2020. Table 1 shows the number of students that participated from each university. 
Table 1: Student Participants

\begin{tabular}{lc}
\hline University & Students \\
\hline The NorthCap University & 270 \\
Istanbul Bilgi University & 1,085 \\
Universidad Latina de Costa Rica & 1,282 \\
\hline Total & 2,637 \\
\hline
\end{tabular}

Table 2 shows the detailed numerical results for students, where the most relevant findings indicate that most of the students were satisfied or very satisfied with their online learning experience (61\%). A considerable proportion of the participants also reported they most enjoyed not traveling to the campus daily ( $34 \%$ of the total sample), flexibility (27\%), and autonomy in time management (18\%). Most students found online classes less engaging than the face-to-face classes (57\%), whereas only $15 \%$ found online classes more engaging. A majority also reported that they did not learn as much (52\%), but most of them believe the instructors contributed to their learning about the same as in the face-to-face subjects. Students generally reported that assessment was as rigorous and fair as in the face-to-face subjects (52\%); 15\% thought that online assessment was more rigorous. More than $40 \%$ of the students identified the following elements as ones they would like to keep after the emergency remote teaching: (a) online access to recorded classes (73.0\%); (b) all learning materials in digital form (73.5\%); (c) flexibility in attendance to lectures (63.8\%); (d) discussion boards (45.4\%); (e) digital interaction with other students (44.7\%); (f) online access to professors from other campuses/universities (40.6\%); and (g) online access to industry experts (42.2\%).

Table 2 also shows the comparison in the student responses between the three universities.

Table 2: Key Results of Student Survey Overall and by Institution (\%)

\section{Q1: Satisfaction with online experience}

Very dissatisfied

Not very satisfied

Satisfied

Very satisfied

\section{Q2: Enjoyed most about online experience}

Not traveling to the campus daily

Autonomy in time management

The flexibility

The opportunity to interact digitally with faculty and students

The digital learning activities

Others

Q3: Compared with F2F, online classes were

More engaging

As engaging

Less engaging

\begin{tabular}{lcll} 
All (\%) & NCU (\%) & Bilgi (\%) & ULatina (\%) \\
\hline 8.5 & 1.5 & 9.3 & 9.3 \\
30.1 & 18.1 & 29.5 & 33.0 \\
46.4 & 63.7 & 46.0 & 43.0 \\
15.1 & 16.7 & 15.1 & 14.7 \\
& & & \\
34.4 & 40.0 & 23.9 & 42.0 \\
18.5 & 13.0 & 17.0 & 20.9 \\
26.9 & 15.6 & 39.3 & 19.0 \\
7.3 & 14.8 & 5.7 & 6.9 \\
& & & \\
6.8 & 8.5 & 6.0 & 7.1 \\
6.1 & 8.1 & 8.1 & 4.1 \\
& & & \\
15.4 & 9.3 & 15.2 & 16.8 \\
26.8 & 25.6 & 25.0 & 28.6 \\
57.8 & 65.2 & 59.8 & 54.5 \\
\hline
\end{tabular}




$\begin{array}{llll}\text { All (\%) } & \text { NCU (\%) } & \text { Bilgi (\%) } & \text { ULatina (\%) } \\ & & & \\ & & & \\ 11.0 & 7.0 & 14.4 & 9.0 \\ 36.6 & 30.4 & 31.7 & 42.0 \\ 52.4 & 62.6 & 53.9 & 49.0 \\ & & & \\ & & & \\ 18.2 & 28.5 & 20.8 & 13.8 \\ 57.7 & 56.3 & 49.6 & 64.7 \\ 24.1 & 15.2 & 29.6 & 21.5 \\ & & & \\ 15.7 & 14.8 & 16.2 & 15.4 \\ 52.8 & 53.0 & 46.8 & 57.6 \\ 31.6 & 32.2 & 36.9 & 27.0\end{array}$

Finally, as presented in Figure 1, a majority of the students (57\%) expressed their preference toward a hybrid modality. This compares with $12 \%$ who preferred online and $31 \%$ who preferred a face-to-face learning experience.

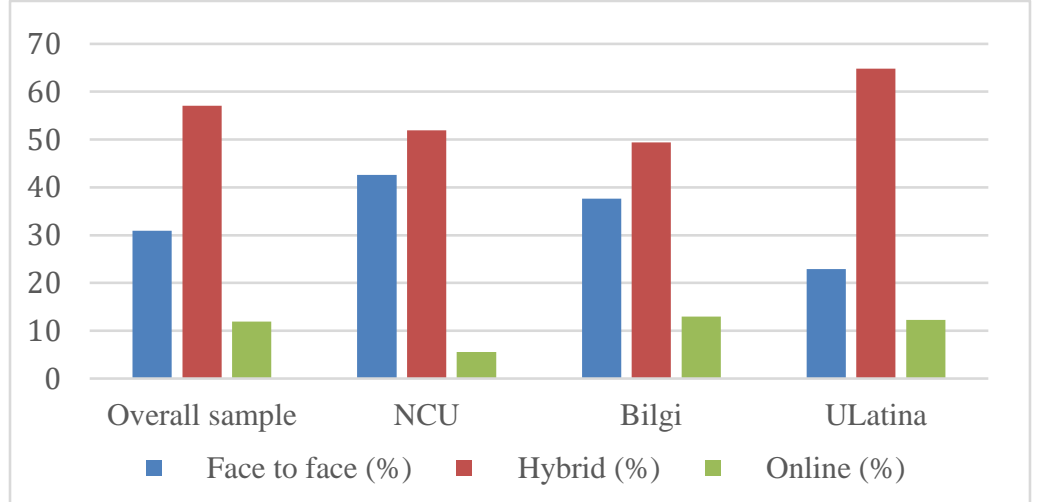

Figure 1: Students Preference Regarding Learning Modality

\section{Faculty survey}

The survey for faculty was also conducted during the month of May 2020. Table 3 shows the number of faculty that participated from each university. 
Table 3: Faculty Participants

\begin{tabular}{lc}
\hline University & Faculty \\
\hline The NorthCap University & 66 \\
Istanbul Bilgi University & 139 \\
Universidad Latina de Costa Rica & 174 \\
\hline \multicolumn{2}{c}{ Total } \\
\hline
\end{tabular}

Table 4 presents the key numerical results, where it can be appreciated that most faculty members were satisfied or very satisfied with their recent online teaching experience (82\%). Most of them reported that they had learned very much or quite a lot (89\%). Most considered themselves sufficiently prepared (56\%), but only $31 \%$ thought that the students were prepared. For the faculty, the institution, external resources, and their colleagues were the major sources of support they received, and very few of them considered the support of their supervisors relevant in their performance.

Table 4: Key Results of Faculty Survey Overall and by Institution (\%)

\section{Q1: Satisfaction with online experience}

All (\%) NCU (\%) Bilgi (\%) ULatina (\%)

Very dissatisfied
Not very satisfied
Satisfied
Very satisfied
Q2: Amount of Learning during online
teaching

$\begin{array}{cccc}1.9 & 0.0 & 3.6 & 1.1 \\ 15.6 & 3.0 & 21.7 & 15.5 \\ 57.7 & 68.2 & 60.9 & 51.1 \\ 24.9 & 28.8 & 13.8 & 32.2\end{array}$

Nothing at all

Not much

0.5

0.0

1.4

0.0

Quite a lot

11.1

4.5

13.7

11.5

Very Much

56.1

61.2

36.2

39.6

39.4

23.7

52.3

Q3: Faculty sufficiently prepared for online teaching
Yes
No
Q4: Students sufficiently prepared for online teaching
Yes
No

Q6: Compared with F2F, online classes were

More engaging

As engaging

Less engaging
30.9

69.1

51.5

48.5

6

41

53

4

8
48
44

30.9

23.0

$69.1 \quad 77.0$ 


\section{All (\%) NCU (\%) $\quad$ Bilgi (\%) $\quad$ ULatina (\%)}

\section{Q7: Compared with F2F, in online classes students learned}

More
As much
Less
Q8: Compared with F2F, in online classes
students enjoyed

More
As much
Less
Q9: Compared with F2F, assessment in
online classes was

More rigorous and fair

As rigorous and fair

$\begin{array}{cccc}18 & 9 & 3 & 5 \\ 60 & 64 & 47 & 68 \\ 35 & 27 & 50 & 27\end{array}$

Less rigorous and fair

$\begin{array}{cccc}8 & 17 & 6 & 7 \\ 41 & 42 & 28 & 52 \\ 50 & 41 & 65 & 41\end{array}$

Q10: Future teaching practice will benefit from this recent online teaching experience

Not at all
Not sure
Possibly yes
Yes, very much
Q11: Digital components of
teaching/learning experience should be
enhanced

Yes

$95 \cdot 3$

$7 \cdot 7$

37.2

9

61

3

7

61

33

30

50

69

53.0

0.0

3.6

1.7

6.1

10.8

5.7

42.4

41.0

32.2

$\begin{array}{lll}51.5 & 44.6 & 60.3\end{array}$

No

93.9

89.9

100.0

Q12: Faculty should be supported and trained to do online teaching

Yes

92.3

97.0

82.7

98.3

No

3.0

17.3

1.7

Similar to the student responses, the majority of the faculty members thought that students found their online classes less engaging than their face-to-face classes (53\%), and 50\% thought that in comparison with face-toface, students enjoyed the online classes less. However, $60 \%$ of the faculty reported that students learned as much in the online classroom as in the face-to-face teaching, and $61 \%$ considered that the assessment of student learning in the online subjects was as rigorous and fair as in the face-to-face subjects. More than $40 \%$ of the faculty members selected the following elements as something they would like to keep: (a) online access to recorded classes (52\%); (b) all learning materials in digital form (77\%); (c) flexibility in attendance to lectures (45.9\%); (d) discussion boards (52.5\%); (e) digital interaction between students (52\%); and (f) online quizzes (41.7\%).

Nearly all (90\%) of the faculty members admitted that their future teaching practice will benefit from this recent online teaching experience. A large group even said it will benefit them very much. Also, $95 \%$ think the 
digital components of the teaching/learning experience should be enhanced in the future, and $92 \%$ believe that faculty should be supported and trained to do online teaching.

Finally, as shown in Figure 2 and consistent with student responses, the majority of faculty (79\%) reported that if students could choose, they would recommend a hybrid mode of delivery, and only $4 \%$ would recommend fully online.

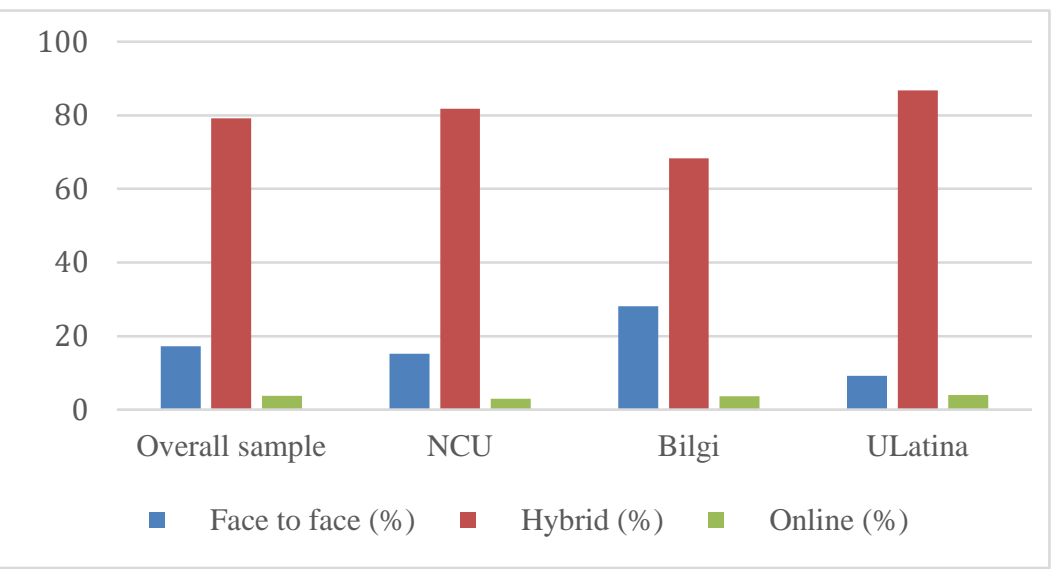

Figure 2: Faculty Preference Regarding Learning Modality

\section{Qualitative}

\section{Student Focus Groups}

A total of four student focus groups were conducted that included a total of 17 participants. Five students participated in one focus group at NCU, six students in two focus groups at Bilgi, and six students in one focus group at ULatina. Overall, students of all three institutions were generally satisfied with the online classes they received, but they acknowledge that the experience lacks the physical interaction with their classmates and teachers. Students noted they missed "dressing up for school," learning experiences that depend on physical interaction, and, in particular, the student-to-student dialogue, which they felt was not the same as when they get together in the classroom.

The majority of focus group participants in all three institutions echoed the student survey results by stating that they felt they learned more in face-to-face classes, though they also realized that the courses were not originally meant to be taught online. They appreciated their instructors' efforts to offer them the best experience possible under the emergency conditions. The students from NCU expressed this idea very clearly: "How all the faculties and the staff of NCU prepared in two days' time, that was commendable and it was all well managed throughout." In terms of infrastructure and support, the student experience was generally positive. Students in ULatina appreciated the swift and competent action on the part of their university in transiting to online education. NorthCap students indicated that their university switched to online mode in just two days over a weekend without any interruption in their studies. They affirmed the choice of learning management system (LMS) platform, which made adaptation easier. At Bilgi, students remarked on the readily available online learning infrastructure and their ability to connect to synchronous courses from multiple smart devices.

Students of all three institutions concurred that while the adaptation process has been easy and effective for theoretical courses, it has been more difficult for courses with labs, applications, or internships. According to ULatina students, lab-based courses, when done online, lacked some of the important aspects of interaction and learning. At Bilgi, where there are extensive applied vocational studies programs like health sciences, civil 
aviation, and culinary arts, students felt the limitations of the virtual environment. At NorthCap, the feedback concurred with that of Bilgi and ULatina by stating that "hands on experience was missing, no hardware experiments could be performed and virtual labs could not fill the gap."

At all three institutions, students say they liked the flexibility of online classes. Students at NCU refer to this idea in a very spontaneous manner: "Get up, open your laptop and it's done. Very convenient!" Bilgi students pointed out that "the recording of virtual classes was a great advantage for us, they should do that for face-toface courses when we return to normal mode."

They feel it is more comfortable for them, and they are saving a lot of time and money, because they don't have to leave their houses. At ULatina, this has been reflected in lecture attendance, which they think has improved. In NorthCap, the students liked the ability to rest in bed while following courses. Bilgi students found it most advantageous that online courses solved the problem of commuting to campus through the notorious Istanbul traffic. Students from the three institutions noted that the instructors showed a lot of commitment, empathy, and understanding given the enormous psychological pressure during the lockdown. ULatina students appreciated their instructors' support for the different situations that they encountered because of the pandemic, such as increased stress, anxiety, and connectivity issues, while those in Bilgi felt that the process contributed positively to their personal dialogue with instructors. NorthCap students observed the occasional intervention of faculty children during lessons and found that seeing their instructors as parents was very interesting.

In terms of disadvantages, ULatina students reported connectivity issues as having a negative impact on their lessons, while Bilgi students found the virtual classroom tool a bit cumbersome. NorthCap students observed the absence of a board and marker (a blackboard experience) as a negative for their learning process. In all three institutions, students indicated the absence of face-to-face interaction negatively impacted learning and participation.

In terms of assets for the future, the flexibility introduced by the recording of lectures has been enjoyed the most by the students. Thus, for the future, students in all three universities concurred that recorded lectures should be a permanent feature of education. Bilgi students indicated that elective courses with a predominantly theoretical content should be delivered fully online, while in general courses it should be delivered in a blended fashion. NorthCap students said they enjoyed this new learning experience in the online platform and wanted more of it. ULatina students indicated that recorded sessions and virtual dialogue with their instructors should become a part of their curriculum.

\section{Faculty Focus Groups}

Three focus groups were conducted with the participation of 22 faculty members. Five faculty members participated in one focus group at the NorthCap, 11 in one focus group at Bilgi, and six in one focus group at ULatina.

Overall, faculty members seemed to feel satisfied with their experience in switching to online classes as an emergency measure due to COVID-19. However, they stressed that this experience is not the same as an online education planned in advance and that most of the faculty were doing this without the appropriate training or accumulated knowledge in online technology, tools, and pedagogy.

At all three institutions, a key aspect was the training that most of them received on online teaching platforms and methodologies in the wake of the emergency. In ULatina, this training helped them to have a smoother transition because it provided options of different didactic activities they could use in their classes. At Bilgi, most faculty adapted their courses to flipped methodology, made greater use of recorded sessions, and gradually increased the amount of synchronous sessions. In NCU, the faculty found that since body gestures were often missing, they could not assert whether the delivery was successfully conducted as they would do in 
the physical class. Other mechanisms, like instant polling or short online quizzes, were introduced to reinforce student attention and understanding, which faculty would like to keep using in the future.

The majority of faculty found the initial stage of the transition the most difficult. At Bilgi, the absence of readily available digital material was noted as an initial challenge, which forced faculty to rapidly produce digital content in quantity. At NCU, the faculty experienced a mix of both being apprehensive and overwhelmed, and they found online teaching a great opportunity to learn new skills (e.g., "I felt initially apprehensive, but later found the experience very good"). At ULatina, the possibility to share experiences and get support among faculty has been found to be useful and they appreciated every opportunity they have had to do so.

The attitude of students was viewed differently among the three institutions. At ULatina, faculty remarked that this new environment for courses has improved student creativity. They were satisfied with some of the different and innovative ideas that students used to develop their projects. This has given them the opportunity to learn together and to learn from the students as well. At NCU, faculty found the online teaching experience good as there was regular and improved participation of students in online classes. The teachers also admitted that their bias toward certain students in the face-to-face classroom disappeared, which made the others feel more comfortable. They also appreciated less distraction and better class performance in many of the students. At Bilgi, faculty observed that the students used their time in a much more self-paced manner, and, although the overall motivation appeared to have dropped, the more engaged students easily adapted to the new environment and performed as well as they did in face-to-face classes, while students with lower academic or digital competency performed worse, a result that was also reflected in the exam performance of students.

In terms of challenges, ULatina faculty observed that one of the biggest difficulties they encountered was the first-year students or newcomers. First-year students did not know how the university worked and were not familiarized with the technological tools offered by the institution. It was a double challenge for them. Furthermore, first-year students needed closer guidance from the administrative staff as well as from their faculty. Bilgi faculty struggled to keep the students with low digital competency or poor digital infrastructure conditions in the fold, while NCU faculty observed that though students became very self-disciplined and selfreliant, not all students could keep up with the workload.

At Bilgi and ULatina, interaction in synchronous classes proved to be a challenge, especially in big groups, as it was difficult to motivate students to interact among themselves despite the variety of methods faculty tried. NCU faculty remarked that because eye-to-eye contact was missing and they were not able to give individual attention to students, often they were not sure if the students were actually listening to them during the synchronous classes. One of the faculty members stated, "We could not see all students and I felt like I was talking to myself." Still, they also noted that some students who were not so participative and shy in face-toface class engaged openly in discussions and asked questions. They also mentioned that there was an aspect that made class management easier; this was the fact that there was no chatter among students. Faculty at the three institutions indicated that the recording of classes and their availability for later viewing through different devices improved student comprehension of subjects. One of the faculty members at Bilgi shared that in his experience, "most students opted to watch lectures in their own time." The recorded sessions were seen as a major bonus to be kept for the future, a finding that echoes the student sentiment on the subject.

ULatina faculty considered lab courses the area where they had to make more adaptations, especially in the assessment area. In Bilgi, the faculty stressed that it was harder to adapt courses with labs, internships, or applied sessions, such as workshops, while lecturers of theoretical courses reported greater success and satisfaction. NCU faculty echoed the student sentiment by stating that hands-on experience was missing, no hardware experiments could be performed, and virtual labs could not fill the gap. 
Another common theme among the faculty was their preference of blended/hybrid course design for the future. One of the Bilgi faculty members expressed her conviction saying, "I will convert most of the theoretical material to digital and upload it to the LMS." At ULatina, while indicating that this new mode of teaching has increased their workload, the challenge of designing new courses with more digital components was met with enthusiasm among the faculty. Bilgi faculty contended that they would convert the theoretical parts of their courses to online, use virtual office hours, and add more digital components to their face-to-face courses, thereby delivering them in a blended fashion. It was also pointed out that online classes have a larger reach and permitted more effective use of resources, which will probably help increase enrollment of students in the future.

\section{Discussion}

If the results of the present study are any indication, the future of face-to-face higher education is hybrid. An overwhelming majority of the faculty members and students who participated in the study think the digital components of the teaching/learning experience should be enhanced and would like to keep some of the forms of learning and interacting they have recently discovered. In particular, they think there should be more flexibility in the physical attendance to lectures, and both faculty and students would appreciate having access to all learning materials in digital form. Digital interaction between students and faculty, including discussion boards, should remain. Students see the digital component of their learnings as a window to connect with other professors and industry practitioners and would like to enjoy that opportunity. Faculty think that online quizzes are a very effective learning tool that should be part of the student's learning experience in the future. It is interesting to see that students did not consider the quizzes as relevant as did faculty, and faculty did not consider the online access to professors from other campuses/universities or to industry experts as relevant as did students. Beyond the concrete enumeration of the most suitable digital components, several of the experiences described in the literature review, by authors like Moreira (2016) and Sun and Chen (2016), can help institutions define the overall picture and key initiatives to deliver education in a hybrid modality.

Faculty and students show high levels of gratitude toward their institutions and high satisfaction levels with the recent online teaching-learning experience. In agreement with authors like Strielkowski (2020), the study confirms how some academic innovations that would have normally taken much longer to occur have been rapidly introduced during the pandemic situation. In this respect, despite Bilgi and ULatina not having a proctoring system yet, it is interesting to learn that even the assessment process was considered by many of the participants to be as rigorous and fair as in the face-to-face delivery. However, many of the participants think that as a community they were not completely ready, and the majority of students feel that the face-toface classes are more engaging and learning is more effective. The study reveals that the social interaction between students was missed, and some of the learning effectiveness resulting from peer interactions was possibly lost. The results of the study also show very low interest in keeping simulated laboratories; faculty and students clearly prefer to use physical labs for this type of practical learning activity. It will be interesting to learn how much of this perception is a result of a very limited planning process that may not have allowed institutions to identify the best digital solutions or address the pedagogical readiness of faculty for their introduction.

Most of the faculty members had no experience in online teaching, and, in a completely unexpected manner, they had to start teaching online. They learned a lot, and they consider that this online immersion will be very valuable for their professional future. Innumerable resources have been recently made available to them, and it will be easier now to continue perfecting their performance. As mentioned before, Crawford (2020) constitutes a good example of recommendations to assist remote instructors. 
However, faculty members felt the delivery mode was not ideal, and the effectiveness in achieving the learning outcomes was not as satisfactory as it would have been if they had taught their subjects face to face. Consistently with this thought, the great majority of the faculty members believe that faculty should be supported and trained to do online teaching. It is interesting to remark that in the qualitative study, the faculty members who had online experience showed more confidence and satisfaction with their outcomes. It seems a clear conclusion that faculty training, support, and experience will be critical elements in the future improvement of an online/hybrid delivery mode. It is also very revealing to think that faculty did not explicitly mention artificial intelligence (AI) or learning analytics as a relevant mechanism to support the personalization of the learning process, but this is clearly an area of major potential impact on the effectiveness of their work that institutions need to consider.

The lack of similar research initiatives during the time of COVID-19 impedes the generalization of some of our takeaways, but as an emergency measure, we can presume that the recent online teaching/learning experience worked well, and it is a clear recommendation to enhance the presence of digital components when the new normality comes. If another episode like COVID-19 occurred, universities would be more prepared, but even if it didn't, the preferences and expectations of students and faculty are clearly inclined toward a hybrid educational mode. In this context, it seems necessary to now move to the next level of learning effectiveness and overall quality in the digital part of the equation. Beyond the necessary investments in technology and the technological and pedagogical development of faculty, the authors of this paper believe that it will also be necessary to switch from a professor-centered course design, where the subject matter experts have played a predominant role, to a team effort where instructional designers will help create the best hybrid learning experiences. Much more thorough strategic planning will be necessary at an institutional level, and major changes in resource allocation and organizational processes and structures will have to be introduced.

\section{Study Limitations}

Given that this study addresses a very recent situation, one important limitation the authors found is the lack of previous research studies on the topic, which reduces possible comparisons, confirmations, or the inclusion of further references. Additionally, the authors reflected on the possible bias that may have been introduced in the sample selection. The countries where the study has been conducted inevitably introduce some cultural bias. Furthermore, since the communication was done via e-mail, the survey was online, and the focus groups were organized online, one may think that the volunteer participants could have a technological profile that affects results to some extent. Finally, it is important to understand that it is not the goal of this study to conduct a thorough analysis of the differences between the institutions, which would require further statistical analysis and the understanding of contextual and cultural differences that this study does not incorporate.

\section{Implications for Theory and Practice}

This study may have some impact on future research initiatives, and the present results will possibly be complemented by further studies carried out in other institutions and countries. However, the aspiration of the authors of this paper would be to inform decision making and inspire initiatives led by institutional leaders and policy makers.

The first proposal would be to conduct student and faculty surveys to check the pulse of the institutions and gather first-hand opinions and recommendations regarding future improvements in higher education. It also seems clear that face-to-face institutions should enhance the digital component of the teaching and learning process, even after life on campuses returns to normal. To do this, universities will need to develop a completely new instructional design, taking students and faculty beyond the limited online experience they have had in the first few months of the pandemic. 
The results of this study suggest that faculty lectures should be recorded and attendance of them become more flexible. Students and faculty should have opportunities to communicate digitally and to include other participants, like industry practitioners or international faculty in the teaching-learning process. Technology also offers numerous opportunities to enhance the active participation of students, with quizzes and discussion boards that were highly appreciated and should be implemented as part of the learning experience. Institutions should also make sure that they provide faculty with the necessary technical and pedagogical support, since many of the elements of the teaching-learning process, and their appropriate operational implementation, will be new for faculty. The enhancement of the role of the instructional designers offers a particularly good opportunity for institutions to define effective learning experiences and to establish successful support initiatives.

\section{Conclusion}

COVID-19 has had terrible consequences; at the writing of this paper, nearly one and a half million deaths have been reported. The damage to global and local economies is unprecedented, and the increase of inequality and lack of opportunities for the less prosperous communities is alarming. However, the authors of this paper believe that this pandemic has brought along some positive effects and improvement opportunities in higher education, and, if the results of the present study are any indication, the future of higher education is in hybrid modes of instruction. Higher education is now better prepared to accept and include technology as an essential component of the learning process that can make the learning experience of the face-to-face students more flexible and engaging. Institutions, technology partners and even the regulatory systems conform now a more favorable context to spur a more effective approach to education that can ideally result in broader access and more effective learning. 


\section{References}

Bao, W. (2020). COVID-19 and online teaching in higher education: A case study of Peking University. Human Behavior and Emerging Technologies, 2(2), 113-115. https://doi.org/10.1002/hbe2.191

Benito, A. \& Díez, E. (2020). Thriving while going online in times of crisis. https://www.cintana.com/insights/thriving-while-going-online-in-times-of-crisis

Blankenberger, B., \& Williams, A. M. (2020). COVID and the impact on higher education: The essential role of integrity and accountability. Administrative Theory \& Praxis, 1-20. https://doi.org/10.1080/10841806.2020.1771907

Cerdas, D., \& Bosque, D. (2020, March 9). 'U' privadas piden permiso para dar clases virtuales por nuevo coronavirus en Costa Rica; 'U' públicas toman otras medidas. La Nación. https://www.nacion.com/elpais/educacion/universidades-privadas-solicitan-permiso-aconesup/NL5TPQB2CVEATFIIZYSDOMVUW4/story/

Crawford, S. (2020). Five tips for remote teaching. Quality Matters. https://www.qualitymatters.org/qaresources/resource-center/articles-resources/higher-ed-remote-teaching-tips

Daniel, S. J. (2020). Education and the COVID-19 pandemic. Prospects, 1-6. https://doi.org/10.1007/s11125020-09464-3

Dumford, A. D., \& Miller, A. L. (2018). Online learning in higher education: Exploring advantages and disadvantages for engagement. Journal of Computing in Higher Education, 3O(3), 452-465. https://doi.org/10.1007/s12528-018-9179-Z

Langella, M. (2020, April 30). COVID-19 and higher education: Some of the effects on students and institutions and how to alleviate them. LSE BPP. https://blogs.lse.ac.uk/politicsandpolicy/covid19higher-education/

Lederman, D. (2020). Preparing for a fall without in-person classes. Inside Higher Ed. https://www.avnetwork.com/news/preparing-for-a-fall-without-in-person-classes-inside-higher-ed

Lee, K. (2017). Rethinking the accessibility of online higher education: A historical review. The Internet and Higher Education, 33, 15-23. https://doi.org/10.1016/j.iheduc.2017.01.001

McKenzie, L., Lederman, D., Burke, L. (2020). Taking colleges online: How smart institutions and their leaders can approach online education now and in a postcoronavirus world. Inside Higher Ed. https://www.insidehighered.com/content/taking-colleges-online-how-smart-institutions-and-theirleaders-can-approach-online

Ministerio de Salud. (2020, March 6). Caso confirmado por COVID-19 en Costa Rica. https://www.ministeriodesalud.go.cr/index.php/centro-de-prensa/noticias/741-noticias-2020/1555caso-confirmado-por-COVID-19-en-costa-rica

Ministerio de Salud. (2020, March 16). Gobierno declara estado de Emergencia Nacional, impide llegada de extranjeros y se suspende lecciones en todos los centros educativos del país. https://www.ministeriodesalud.go.cr/index.php/centro-de-prensa/noticias/741-noticias-2020/1572gobierno-declara-estado-de-emergencia-nacional-impide-llegada-de-extranjeros-y-se-suspendelecciones-en-todos-los-centros-educativos-del-pais

Moreira, D. (2016). From on-campus to online: A trajectory of innovation, internationalization and inclusion. International Review of Research in Open and Distributed Learning, 17(5), 186-199.

https://doi.org/10.19173/irrodl.v17i5.2384. 
Muir, T., Milthorpe, N., Stone, C., Dyment, J., Freeman, E., \& Hopwood, B. (2019). Chronicling engagement: students' experience of online learning over time. Distance Education, 4O(2), 262-277. https://doi.org/10.1080/01587919.2019.1600367

Núñez-Moscoso, J (2017). Mixed methods in educational research: Towards reflective use. Cuadernos de Pesquisa, 47 (164), 632-649. https://doi.org/10.1590/198053143763

Ortagus, J. (2018). From the periphery to prominence: An examination of the changing profile of online students in American higher education. The Internet of Higher Education, 32, 47-57. https://doi.org/10.1016/j.iheduc.2016.09.002

Pathak, B. K. (2016). Emerging online educational models and the transformation of traditional universities. Electronic Markets, 26(4), 315-321. https://doi.org/10.1007/s12525-016-0223-4

Petrone, P. (2020, February 23). Suddenly teaching online? Resources to help faculty affected by coronavirus LinkedIn Learning [Blog post]. https://learning.linkedin.com/blog/learning-thoughtleadership/suddenly-teaching-online--free-resources-to-help-faculty-affecte?trk=eml-mktg-ldc20200414-cq420v-19cc-higher-education-teaching-online-campaign\&src=eeml\&mcid $=6651517651984220160 \&$ cid $=7010$ doo000 $1 \mathrm{KxSAAAS}$

Sahu, P. (2020). Closure of universities due to Coronavirus Disease 2019 (COVID-19): Impact on education and mental health of students and academic staff. Cureus, 12(4). 10.7759/cureus.7541

Strielkowski, W. (2020) COVID-19 Pandemic and the Digital Revolution in Academia and Higher Education. Preprints. 10.20944/preprints202004.0290.v1

Sun, A., \& Chen, X. (2016). Online education and its effective practice: A research review. Journal of Information Technology Education, 15, 157-190. https://doi.org/10.28945/3502

Toquero, C. M. (2020). Challenges and opportunities for higher education amid the COVID-19 pandemic: The Philippine context. Pedagogical Research, 5(4) emoo63. https://doi.org/10.29333/pr/7947

Turkish Board of Higher Education (2020). Assessment note. https://www.yok.gov.tr/Sayfalar/Haberler/2020/uzaktan-egitime-yonelik-degerlendirme.aspx accessed 04.05.2020

van Dijk, T. A. (2016). Estudios críticos del discurso: Un enfoque sociocognitivo. Discurso \& Sociedad, 1O(1), 137-162. http://repositorio.ciem.ucr.ac.cr/bitstream/123456789/230/1/RCIEM208.pdf

van Dijk, T. A. (2018). Discourse and migration. In R. Zapata-Barrero, \& E. Yalz (Eds.), Qualitative Research in European Migration Studies (pp. 227-245). Springer. https://doi.org/10.1007/978-3-319-76861-8 13

Vlachopoulos, D. (2016). Assuring quality in e-learning course design: The roadmap. International Review of Research in Open and Distributed Learning, 17(6), 183-205. https://doi.org/10.19173/irrodl.v17i6.2784 


\section{Appendix A: Student Survey}

\section{Demographics}

- What is your age? $18-25,26-40$, Older than 40, prefer not to reveal

- What is your degree level? Bachelor Y1, Bachelor Y2, Bachelor Y3, Bachelor Y4, master, PhD, prefer not to reveal

- What is your gender? Male, Female, Prefer not to reveal

1. How satisfied are you with your recent over all university experience?

- Very satisfied

- $\quad$ Satisfied

- $\quad$ Not very satisfied

- $\quad$ Very dissatisfied

2. What did you enjoy the most of your online experience?

- $\quad$ Not travelling to the campus daily

- The autonomy in time management

- The flexibility

- The opportunity to interact digitally with faculty and students

- The digital learning activities

- $\quad$ Others (please mention)

3. In general, how engaging were the online classes?

- More engaging than the face to face classes

- As engaging as the face to face classes

- Less engaging than the face to face classes

4. In general, how much did you learn in your online subjects?

- More than in the face to face subjects

- As much as in the face to face subjects

- Less than in the face to face subjects

5. In general, did the instructors contribute positively to your development in the online subjects?

- Instructors contributed more than in the face to face subjects

- Instructors contributed about the same as in the face to face subjects

- Instructors contributed less than in the face to face subjects

6. In general, how was the assessment of your learning in the online subjects?

- More rigorous and fair than in the face to face subjects

- As rigorous and fair as in the face to face subjects

- Less rigorous and fair than in the face to face subjects

7. Please select only those you would like to keep:

- $\quad$ Online access to recorded classes

- All learning materials in digital form

- Flexibility in attendance to lectures

- Discussion boards

- Digital interaction with other students

- Online office hours of professors

- Online tutoring/mentoring sessions

- $\quad$ Use of digital interactive tools (Kahoot, IdeaBoards, others...)

- Simulation labs

- Online quizzes 
- Online self-assessments

- Online access to professors from other campuses/universities

- Online access to industry experts

- Others (please mention)

8. What kind of learning experience do you prefer?

- Face to face

- Hybrid (a combination of face to face and online)

- Online 


\section{Appendix B: Faculty Survey}

Profile:

- How many years of teaching experience do you have? 1-5 years, 6-10 years, 11-20 years, over 20 years

- In what degree level do you teach? Bachelor, master, $\mathrm{PhD}$

- In what field of knowledge do you teach? Architecture, Basic/applied sciences, Business, Communication, Computer Sciences, Design, Education, Engineering, Health, Social Sciences, Other (mention)

- Did you have previous experience in online teaching? Yes/No

- What is your gender? Male, Female, Prefer not to reveal

1. How satisfied are you with your recent online teaching experience?

- Very satisfied

- $\quad$ Satisfied

- $\quad$ Not very satisfied

- Very dissatisfied

2. How much did you learn during this online teaching experience?

- Very much

- Quite a lot

- Not much

- Nothing at all

3. Do you consider you were sufficiently prepared for online teaching before starting?

- Yes

- No

4. Do you consider the students were sufficiently prepared for online learning?

- Yes

- No

5. Who helped you the most during your online teaching experience?

- The institution

- My supervisor

- My colleagues

- The students

- External resources, best practices and recommendations

- Others (mention)

6. In comparison with face to face, how engaging do you think students found your online classes?

- $\quad$ More engaging than the face to face classes

- As engaging as the face to face classes

- Less engaging than the face to face classes

7. In comparison with face to face, how much do you think your students learnt in your online subjects?

- More than in the face to face subjects

- As much as in the face to face subjects

- Less than in the face to face subjects

8. In comparison with face to face, how much do you think your students enjoyed your online classes?

- More than in the face to face classes

- As much as in the face to face classes

- Less than in the face to face classes 
9. In comparison with face to face, how was the assessment of your students' learning in the online subjects?

- More rigorous and fair than in the face to face subjects

- As rigorous and fair as in the face to face subjects

- Less rigorous and fair than in the face to face subjects

10. Please select only those you would like to keep:

- $\quad$ Online access to recorded classes

- All learning materials in digital form

- Flexibility in attendance to lectures

- Discussion boards

- Digital interaction between students

- Online office hours

- Online tutoring/mentoring sessions

- Use of digital interactive tools (Kahoot, IdeaBoards, others...)

- Simulation labs

- Online quizzes

- Online self-assessments

- Online access to professors from other campuses/universities

- Online access to industry experts

- Others (please mention)

11. Do you think your future teaching practice will benefit from this recent online teaching experience?

- Yes, very much

- Possibly yes

- Not sure

- Not at all

12. Do you think the digital components of the teaching/learning experience should be enhanced in the future?

- Yes

- No

13. Do you think faculty should be supported and trained to do online teaching?

- Yes

- No

14. If a student could choose, which mode of delivery would you recommend?

- Face to face

- Hybrid

- Online

The Higher Learning Research Communications (HLRC), is a peer-reviewed, online, interdisciplinary journal indexed in Scopus, ERIC, JGATE and Directory of Open Access Journals (DOAJ). It is an open access journal with an international focus published by Walden University, USA. Its aim is to disseminate both high quality research and teaching best practices in tertiary education across cultures and disciplines. HLRC connects the ways research and best practice contribute to the public good and impact the communities that educators serve. $H L R C$ articles include peer-reviewed research reports, research briefs, comprehensive literature reviews, and books reviews. 